\title{
PERFIL DOS ACADÊMICOS INGRESSANTES NO CURSO DE EDUCAÇÃO FÍSICA BACHARELADO EM RELAÇÃO AOS TURNOS
}

\author{
Eloah Silva Marcilio ${ }^{1}$ \\ Jéssica Stephanie de Oliveira Tulio ${ }^{2}$ \\ Célia Cristina Fornaziero ${ }^{3}$ \\ Eduardo Vignoto Fernandes ${ }^{4}$
}

MARCILIO, E. S.; TULIO, J. S. de O.; FORNAZIERO, C. C.; FERNANDES, E. V. Perfil dos acadêmicos ingressantes no curso de Educação Física Bacharelado em relação aos turnos. EDUCERE - Revista da Educação, Umuarama, v. 21, n. 2, p. 211-226, jul./dez. 2021.

RESUMO: Entender o perfil dos acadêmicos ingressantes em um curso de graduação é essencial para um planejamento curricular que contemple o contexto social. Nesse sentido, as disparidades encontradas entre os estudantes de um mesmo curso levam à necessidade constante de aprimoramento das atividades acadêmicas propostas. Esse trabalho objetiva compreender o perfil e a motivação do ingressante de Educação Física Bacharelado de uma instituição pública. A metodologia baseouse na aplicação de questionários aos estudantes do primeiro ano do curso que se voluntariaram durante as aulas de Anatomia Humana, sendo os dados posteriormente analisados por meio do uso do índice de significância mínimo. Após a análise, evidenciaram-se diferenças significativas entre os turnos, sendo os acadêmicos do período matutino, mais jovens em relação aos do noturno. Ainda, a maior parte dos ingressantes, independente do turno, reside com pais, parentes e irmãos, porém, os primeiros também compartilham residência com amigos, enquanto os segundos, com companheiros/filhos. Em relação ao tempo de preparo para as avaliações, estudantes do matutino estudam diariamente; ao passo que a maioria do noturno se dedica apenas no dia anterior às avaliações. Em geral, os acadêmicos desse

DOI: $10.25110 /$ educere.v21i2.2021.8528

${ }^{1}$ Universidade Estadual de Londrina. eloah.silva.marcilio@uel.br. http://orcid.org/0000-0002-4477-402X

${ }^{2}$ Universidade Estadual de Londrina. jessica.tulio1@uel.br. http://orcid.org/0000-0003-3169-8934

${ }^{3}$ Universidade Estadual de Londrina. celiafornaziero@uel.br. http://orcid.org/0000-0002-4208-1844

${ }^{4}$ Universidade Federal de Jataí. eduardovignoto@ufj.edu.br. http://orcid.org/0000-0003-0876-2491 
curso não costumam realizar atividades extraclasse, porém os estudantes do turno matutino estão mais propensos a desempenharem tais atividades. Concluiu-se que a identificação dessas dessemelhanças é fundamental para o desenvolvimento de estratégias diferenciadas de ensino conforme as peculiaridades de cada contexto, contribuindo para a implementação de um processo de ensino e aprendizagem eficaz.

PALAVRAS-CHAVE: Ensino Superior; Escolha da Profissão; Aprendizagem.

\section{PROFILE OF FRESHMEN IN PHYSICAL EDUCATION COURSE IN RELATION TO THE PERIODS}

ABSTRACT: An understanding of the profile of freshman students in a graduation course is essential for curricular planning to include social context. Therefore, the imbalances found among students of the same course have led to the constant need to improve the proposed academic activities. The aim of this paper is to recognize the profile and motivation of freshmen in Physics Education baccalaureate courses in a public institution. The methodology was based on applying questionnaires to first-year students of the course who volunteered during the Human Anatomy classes. The data was subsequently analyzed though the minimum significance index. After the analysis, significant differences were observed among students in different periods, with the students from the morning period being younger than those in the evening period. Furthermore, most freshmen, regardless of the period, live with parents, relatives and siblings, but the former also share accommodations with friends, while the latter with partners/children.. Regarding the preparation time for texts, students in the morning period study daily, while most students in the evening class only dedicate the previous day for evaluations. In general, students in this course do not usually perform extra-class activities, but those in the morning class are more likely to perform such activities. It could be concluded that the identification of those differences is essential for developing differentiated teaching strategies according to the specificities of each context, thus contributing to the implementation of an efficient teaching-learning process.

KEYWORDS: Higher Education; Career Choice; Learning. 


\section{MARCILIO, E. S. et al.}

\section{PERFIL DE LOS ESTUDIANTES QUE INGRESAN EN LA LICENCIATURA DE EDUCACIÓN FÍSICA CON RELACIÓN A LOS TURNOS}

RESUMEN: Comprender el perfil de los estudiantes que ingresan a un curso de pregrado es esencial para una proyección curricular que tenga en cuenta el contexto social. Las disparidades encontradas entre los alumnos de un mismo curso conducen a la constante exigencia de mejora de las actividades académicas propuestas. Este estudio buscó averiguar el perfil y la motivación del estudiante de grado de Educación Física de una entidad pública. La metodología se basó en la aplicación de los cuestionarios a los estudiantes de primer año que se presentaron voluntariamente durante las clases de Anatomía Humana, y los datos se analizaron posteriormente mediante el índice de significatividad mínima. Una vez realizado el análisis, se han evidenciado diferencias significativas entre ambos turnos, siendo los alumnos del periodo de la mañana más jóvenes en relación con los del periodo de la noche. Asimismo, la gran mayoría de los ingresados, al margen del turno, residen con sus padres, familiares y hermanos; sin embargo, los primeros también comparten residencia con amigos, mientras que los segundos, con sus compañeros/ hijos. En lo que respecta al tiempo de preparación de las evaluaciones, los estudiantes del turno de la mañana estudian a diario, mientras que la mayoría de los estudiantes del turno de la noche se dedican únicamente al día anterior a las pruebas. De forma general, los académicos de ese curso no suelen realizar actividades extraescolares, pero los alumnos del turno de la mañana son más propensos a efectuarlas. Se ha concluido que la determinación de estas discrepancias es imprescindible para el fomento de estrategias de enseñanza diferenciadas en virtud de las peculiaridades de cada contexto, contribuyendo a la implantación de un proceso de enseñanza y aprendizaje contextualizado y eficaz.

PALABRAS CLAVE: Educación superior, Elección de Profesión, Aprendizaje.

\section{INTRODUÇÃO}

A Universidade Estadual de Londrina (UEL) se compromete com uma educação superior voltada ao desenvolvimento socioeconômico, político e cultural do Estado do Paraná e do Brasil, procurando garantir a igualdade de acesso e o respeito ao pluralismo de ideias. A UEL acredita que cada curso de graduação 
deve ter seu projeto político pedagógico pautado em conteúdo científico, técnico, filosófico e estético, assim como deve propiciar oportunidades que extrapolam os espaços da sala de aula para formar profissionais com competência técnica e humanística (UEL, 2021a). Dentro desse contexto, o Curso de Educação Física Habilitação Bacharelado oferece caminhos para que o estudante desenvolva suas habilidades de criação e de ampliação de sua autonomia e criticidade, visando à formação de um profissional interessado na promoção do bem-estar humano (UEL, 2021b).

Conhecer o perfil dos acadêmicos é uma forma de compreender o contexto no qual eles estão inseridos, visando à melhora da acessibilidade ao curso e, consequentemente, ao conhecimento, já que possibilita direcionar o ensino para formar profissionais plenamente capacitados (MOURA; MIRANDA; PEREIRA, 2015). Ademais, a maior democratização do acesso à universidade torna necessária a melhora constante da qualidade do ensino superior, baseando-se nas características do ingressante e do curso, no sentido de o conhecimento adquirido pelo acadêmico ser efetivo para o seu desenvolvimento pessoal e profissional (CUNHA, 2015).

Com relação aos ingressantes de Educação Física, é possível constatar que os acadêmicos desse curso de graduação comumente têm algum nível ativo de atividade física (CLAUMANN et al., 2017; KRUG; KRUG, 2017), sendo, portanto, a apreciação pelo exercício físico uma das razões para a escolha do curso. Ademais, há influências de outros fatores intrínsecos ao indivíduo que motivam a escolha da graduação em Educação Física, como identificação com o curso e aspiração por atuar na promoção de saúde (KRUG; KRUG, 2017). Outras características observadas são as especificidades relativas ao sexo - maioria masculina -, à idade - jovens entre 20 e 30 anos - e ao estado civil - maioria solteiro - (PINTO et al., 2017), as quais podem variar de acordo com o turno acadêmico escolhido.

\section{OBJETIVO}

Compreender o perfil e a motivação do ingressante do curso de Educação Física Bacharelado da UEL, analisando a associação entre os discentes dos períodos matutino e noturno. 


\section{METODOLOGIA}

\section{Participantes}

Participaram do presente estudo 132 acadêmicos do Curso de Educação Física Bacharelado, de ambos os sexos, sendo 59 do período matutino e 73 do período noturno. Todos os participantes ingressaram na Universidade Estadual de Londrina (UEL) no ano de 2019 e estavam devidamente matriculados e frequentando o primeiro semestre de graduação.

Os acadêmicos foram recrutados de forma voluntária durante as aulas de Anatomia Humana e os mesmos, após aceitarem participar da pesquisa, assinaram o termo de consentimento livre e esclarecido. O trabalho foi aprovado pelo Comitê de Ética em Seres Humanos da UEL (CAAE: 79469417.4.0000.5231).

\section{Coleta de dados}

Para conhecer os acadêmicos foi passado um questionário para verificar o perfil sociodemográfico, a forma de entrada na instituição, os motivos que levaram a escolha do curso, satisfação com a escolha do curso e envolvimento com as atividades acadêmicas.

Em relação às atividades acadêmicas, foram coletados dados sobre a opinião dos ingressantes em relação ao curso, o nível de participação nas aulas, bem como sua participação em atividades extraclasse e dedicação aos estudos para as avaliações nas disciplinas.

\section{Análises estatísticas}

Para a realização das análises estatísticas, os dados dos questionários foram tabulados e organizados em planilha. Após esse procedimento foi realizada associação entre as variáveis dos estudantes dos turnos matutino e noturno pelo teste Qui-quadrado. O programa estatístico utilizado foi o GraphPad Prism 6.0. Com índice de significância mínimo de $\mathrm{p}<0,05$.

\section{RESULTADOS}

Na Tabela 1 estão apresentadas as associações do perfil sociodemográfico, forma de entrada na universidade, motivos da escolha do curso e envolvimento com 
as atividades acadêmicas dos estudantes do curso de Educação Física Bacharelado em relação aos turnos matutino e noturno.

Em relação à idade, foi observado que os estudantes do matutino são mais jovens (81,3\% - faixa de 17 a 20 anos) que os do noturno (58,9\% - faixa de 17 a 20 anos). Em relação à moradia dos ingressantes foi observado que, independentemente do turno, a grande maioria dos estudantes residem na mesma cidade onde se encontra a UEL, Londrina-PR.

Quando questionado com quem os estudantes residem, independente do período, a maioria vive com os pais, parentes e irmãos. No entanto, mais estudantes do matutino vivem com amigos em repúblicas $(16,9 \%)$ e apenas $4,1 \%$ dos estudantes do noturno vivem com amigos em repúblicas. Além disso, nenhum estudante do matutino vive sozinho ou com companheiro/filhos. Por outro lado, $6,8 \%$ dos estudantes do noturno vivem sozinhos e $5,5 \%$ vivem com companheiro/ filhos.

Em relação à forma de ingresso na UEL, a maioria dos estudantes disse ter entrado pelo sistema universal de vagas e pelo Sistema de Seleção Unificada (SiSU). Além disso, disseram ter escolhido o curso por vocação, estando satisfeitos com o curso e que a participação nas aulas varia de bom a ótimo.

Ao questionar como eles se preparam para as avaliações, foi verificado que $40,7 \%$ dos estudantes do matutino estudam diariamente para as avaliações, ao passo que os estudantes do noturno, em sua maioria $(56,2 \%)$ estudam um dia antes da avaliação. Além disso, a grande maioria dos estudantes, independente do período, não realizaram atividades extraclasse, no entanto, existe uma tendência para os acadêmicos do matutino participarem de atividades extraclasse. 


\section{MARCILIO, E. S. et al.}

Tabela 1: Associação do perfil sociodemográfico, forma de entrada na universidade, motivos da escolha do curso e envolvimento com as atividades de ensino dos acadêmicos do curso de Educação Física Bacharelado em relação aos períodos. Londrina - PR - Brasil, 2019. $(\mathrm{n}=132)$.

\begin{tabular}{lccc}
\hline Variáveis & $\begin{array}{c}\text { Matutino } \\
\text { n }(\%)\end{array}$ & $\begin{array}{c}\text { Noturno } \\
\text { n }(\%)\end{array}$ & p-valor \\
\hline
\end{tabular}

\section{Idade}

17 a 20

$\begin{array}{ccc}48(81,3) & 43(58,9) \\ 06(10,2) & 18(24,7) & \\ 05(8,5) & 12(16,4)\end{array} \quad 0,021^{*}$

26 ou mais

$44(74,6) \quad 51(69,9)$

Londrina

Região metropolitana de Londrina

$12(20,3) \quad 21(28,8)$

0,285

Outras cidades

$03(5,1)$

$01(1,3)$

\section{Com quem reside}

Pais/parentes/irmãos

Amigos

Companheiro/filhos

Sozinho

$\begin{array}{ccc}49(83,1) & 60(83,6) & \\ 10(16,9) & 03(4,1) & \\ 00(0,0) & 05(6,8) & \\ 00(0,0) & 04(5,5) & \end{array}$

Forma de ingresso na UEL

SISU

Universal

Sistema de Cotas

Vagas remanescentes

\section{Por que escolheu o curso}

Vocação

Indecisão e/ou acesso mais fácil

\section{Opinião sobre o curso}

Insatisfatório

Pouco Satisfatório

Satisfatório

Muito Satisfatório

$\begin{array}{clr}30(50,8) & 25(34,2) & \\ 16(27,1) & 28(38,4) & \\ 02(3,4) & 10(13,7) & 0,052 \\ 11(18,6) & 10(13,7) & \end{array}$

$43(72,9) \quad 59(80,8)$

$16(27,1) \quad 14(19,2)$

0,279

$01(1,7) \quad 01(1,4)$

$05(8,5) \quad 06(8,2)$

$37(62,7) \quad 52(71,2)$

0,733 
Nível de participação nas aulas

Ruim

Bom

Médio

$03(5,1) \quad 05(6,8)$

$28(47,5) \quad 34(46,6)$

0,915

Estudo para as avaliações

Dia da avaliação

Dia que antecede a avaliação

Uma semana antes da avaliação

$28(47,5) \quad 34(46,6)$

Diariamente

$02(3,4) \quad 10(13,7)$

$21(35,6) \quad 41(56,2)$

$12(20,3) \quad 04(5,5)$

$0,002 *$

$24(40,7) \quad 18(24,7)$

\section{Participou das atividades extraclasse}

Não

$42(71,2) \quad 61(83,6)$

Sim

$17(28,8)$

$12(16,4)$

0,088

Legenda: SiSU - Sistema de Seleção Unificada; UEL, Universidade Estadual de Londrina; n, número.

\section{DISCUSSÃO}

Ao analisar o perfil dos acadêmicos do presente estudo, evidenciou-se uma heterogeneidade relativa à idade, à moradia, às pessoas com quem residem e ao modo de preparo para as avaliações, sobretudo, quando comparados os turnos matutino e noturno.

Em relação à idade, o presente estudo mostrou que os ingressantes no curso de Educação Física matutino são mais jovens em relação aos do noturno. Segundo Moura, Pereira e Miranda (2015), os acadêmicos do matutino ingressam no ensino superior, ainda jovens e inexperientes, buscando o conhecimento, para, depois, iniciarem o seu primeiro emprego; por outro lado, muitos estudantes do noturno ingressam nas universidades já aderidos ao mercado de trabalho, uma vez que almejam, por meio do acesso ao estudo, alavancar sua vida profissional ou buscarem novas oportunidades. $\mathrm{O}$ fato de os ingressantes do noturno já adentrarem na universidade com objetivos delineados, inclusive profissionalmente, também está aliado, ainda, conforme o estudo de Moura, Pereira e Miranda (2015), com possuírem maior maturidade, pois, mesmo em uma rotina associada ao mercado de trabalho, de acordo com $85,8 \%$ dos docentes entrevistados em tal artigo, esses acadêmicos são mais interessados e aproveitam de forma mais eficaz o tempo que 


\section{MARCILIO, E. S. et al.}

dispõem para os estudos, já que sabem a dificuldade em conciliar estudo e trabalho, influenciando de forma positiva seus desempenhos na universidade.

Ademais, de acordo com Maranhão e Veras (2017), na segunda metade do século XX, as universidades brasileiras iniciaram ofertas de cursos de graduação no turno da noite, sendo essa ampliação regulamentada apenas em 1966, nas universidades públicas, o que possibilitou o acesso à educação às pessoas que trabalhavam durante o dia e que, na maioria dos casos, apresentam idades superiores aos estudantes matriculados no turno matutino. Esse achado corrobora com o estudo de Fraga, Oliveira e Sebastiany (2018), o qual concluiu que, estudantes do noturno ingressam mais tardiamente no ensino superior em relação aos estudantes do matutino devido a sua relação com o mercado de trabalho, evidenciando uma situação socioeconômica mais vulnerável desse grupo.

Quando questionado com quem os estudantes residem, independente do turno, a maioria vive com os pais, parentes e irmãos. Silva (2019) relaciona isso com a dependência financeira, afirmando, ainda, existir maior tendência de os estudantes do matutino residirem com a família e de possuírem maior renda, quando comparada a do noturno. Ademais, esse resultado do estudo pode afirmar uma tendência na atualidade, observada pela UNESCO (2006), de que muitos jovens não pensam em sair da casa dos pais, e os que saem tendem a retornar (SOUZA et al., 2016). Essas decisões, segundo Cobo e Saboia (2010), são influenciadas por questões financeiras, sociodemográficas e psicológicas, implicando graus distintos de dependência familiar e econômica. Soma-se, ainda, conforme Henriques et al. (2007), a horizontalização das relações entre familiares, em que os papéis dos membros sofreram mudanças, gerando um ambiente mais democrático para as relações. Nessas relações a hierarquia encontra-se mascarada, permitindo uma acomodação e adaptação para uma boa e mais prolongada convivência familiar, em que os papéis de pais e filhos se complementam funcionalmente de forma benéfica.

Além disso, foi observado no presente estudo haver, aproximadamente, quatro vezes mais estudantes do matutino vivendo em repúblicas com amigos, quando comparado aos acadêmicos do noturno, reafirmando a propensão de os estudantes do período matutino ainda não estarem inclusos no mercado de trabalho. Isso confirma os achados de Cardoso e Sampaio (1994) sobre o percentual de universitários que não trabalham e dividem residência com amigos $(15,5 \%)$ ser maior em relação aos que realizam atividade remunerada $(6,1 \%)$, evidenciando serem, os primeiros, ainda dependentes financeiramente da família, apesar de já 
morarem separados dela.

Somado a isso, nos resultados desta pesquisa, nenhum estudante do matutino mora sozinho ou com companheiro/filhos, o que se opõe ao observado em uma parcela significativa do noturno. Conforme Silva (2019), em seu estudo feito com acadêmicos do curso de Ciências Contábeis, comparando os turnos noturno e matutino, mais acadêmicos do noturno são casados ou estão em união estável (28\%) do que no matutino (11\%); além de mais acadêmicos do noturno possuírem filhos $(22 \%)$ do que do matutino (11\%), constatando, portanto, a influência do estado civil e da presença ou não de filhos na determinação entre morar sozinho ou não durante a graduação.

Nos resultados obtidos, em relação à frequência de estudo para as avaliações, percebe-se uma prevalência de acadêmicos do matutino que estudam diariamente; em contraste, mais da metade dos matriculados no noturno estudam apenas no dia anterior às provas. O estudo de Carelli e Santos (1998) mostrou a presença dessa diferença entre os turnos dos cursos de Farmácia e Engenharia, em que os alunos do matutino possuíam mais horas de estudo distribuídas durante toda a semana, enquanto os do noturno contavam basicamente com os sábados e domingos, pois dispunham de poucas horas disponíveis de segunda à sexta-feira, não possuindo, assim, tempo suficiente para se dedicarem aos estudos. Isso fica evidente na análise de Silva (2019), pois 47\% dos estudantes de cursos matutinos destinam, no mínimo, 1 hora diária para o estudo e cerca de 49 a 54\% desses acadêmicos estudam, diariamente, entre 2 e 4 horas; já no ensino noturno, em média, $70 \%$ dos entrevistados estudam menos de 1 hora por dia, enquanto apenas de 26 a 33\% estudam entre 2 e 4 horas. A criação desse momento de estudo diário, de acordo com Carvalho (2012), pode auxiliar na utilização eficiente e apropriada do tempo disponível, contribuindo, também, com a compreensão de que uma rotina de estudos é necessária para um bom rendimento e resultado acadêmico.

Ainda, segundo Silva (2019) e Carelli e Santos (1998), verifica-se que, entre os fatores que impactam negativamente na adaptação dos estudantes à vida acadêmica, o principal relato dos alunos do noturno foi a indisponibilidade de tempo por possuir um emprego. Moreira e Gomes (2018), buscaram entender como o trabalho influencia no desempenho acadêmico e, em suas pesquisas, constatouse o prejuízo dessa atividade aos estudos na perspectiva de cerca de $41 \%$ dos acadêmicos. Além disso, comparando alunos do matutino que trabalham, há uma tendência de esses possuírem uma carga horária menor, pois segundo estudo de 


\section{MARCILIO, E. S. et al.}

Amorim, Rodrigues e Rodrigues (2012), realizado com acadêmicos de Química, $16 \%$ dos estudantes do período matutino trabalham cerca de 6 horas diárias, enquanto $54 \%$ dos estudantes do noturno trabalham 8 horas diárias.

$\mathrm{O}$ meio de transporte utilizado para dirigir-se à universidade também pode influenciar na divergência de tempo disponível para dedicar-se ao estudo entre os turnos. Patto, Ferro e Aires (2017) notaram que, dentre os estudantes envolvidos em sua pesquisa, os do matutino não utilizavam transporte de nenhum tipo e $100 \%$ deles chegavam em menos de 30 minutos à instituição; por outro lado, 78\% dos entrevistados do noturno dependiam do transporte coletivo, sendo que $56 \%$ desse período levava entre 30 e 60 minutos e $26 \%$ entre 1 e 2 horas para deslocar-se até a universidade, evidenciando, portanto, um maior tempo gasto pelos estudantes do noturno.

Ademais, Carelli e Santos (1998) apontam condições pessoais, sendo o sono e o cansaço os mais mencionados, como prejudiciais ao rendimento nos estudos do acadêmico do noturno, salientando que estudantes do matutino possuem menos situações pessoais com potencial de prejudicar sua aprendizagem. Assim, além de os primeiros possuírem poucas horas para se dedicarem aos estudos, os fatores sono e cansaço (físico e mental) são agravantes para o bom desempenho acadêmico dos estudantes do noturno. Devido a isso, Camargo e Silva (2006) frisam a importância dos acadêmicos do noturno se manterem mais ativos nas aulas, para isso, uma estratégia seria a participação nas discussões em sala e a troca de informações entre alunos e professores.

Os docentes também podem contribuir, desenvolvendo práticas de ensino com métodos mais interativos, de forma a melhorar o processo de ensino e aprendizagem (SALBEGO et al., 2015). Santos et al. (2020) ainda salienta que cada estudante possui sua própria forma e técnicas de aprendizado, o que torna pertinente a realização de testes, no início da graduação, para identificar essas variações, além de ser importante que o docente exponha diferentes formas pelas quais os conteúdos podem ser apresentados, com o objetivo de que os estudantes optem pelas que mais se adequem ao seu método de aprendizagem. Cabe destacar, ainda, a importância disso no estudo da anatomia, uma das disciplinas do curso de Educação Física, em que várias dificuldades no ensino e aprendizagem são relatadas (PIAZZA; REPPOLD FILHO, 2011).

A relevância dessas ações é auxiliar os estudantes do noturno a aproveitarem melhor o tempo disponível para o estudo, uma vez que, segundo $81 \%$ 
dos docentes entrevistados no estudo de Moura, Pereira e Miranda (2015), esses acadêmicos possuem maior comprometimento com as atividades durante a aula, inclusive em tarefas extraclasse, realizando trabalhos mais estruturados e de maior qualidade, participando mais das aulas e, por isso, demonstrando maior interesse por terem consciência do pouco tempo que possuem para estudo fora da universidade.

Ainda sobre as perguntas realizadas aos acadêmicos envolvidos nesse estudo, foi questionado acerca da participação em atividades extracurriculares, evidenciando um maior envolvimento dos estudantes do matutino $(28,8 \%) \mathrm{em}$ relação aos do noturno (16,4\%). Conforme Moura, Pereira e Miranda (2015), os estudantes do período matutino conseguem ter uma melhor participação em projetos de iniciação científica, palestras e outros eventos do que os do noturno, uma vez que esses possuem menor disponibilidade de tempo para desenvolverem esses tipos de atividades.

Ademais, o trabalho de Maranhão e Veras (2017), que traz a opinião de estudantes desses dois turnos, revela que a universidade, normalmente entendida por uma junção entre ensino, pesquisa e extensão, resume-se, para o período noturno, apenas ao ensino. Isso se deve, de acordo com os autores, ao fato de que frequentemente projetos de pesquisa e extensão são oferecidos durante o dia, período em que muitos dos matriculados no noturno estão trabalhando. Nesse mesmo estudo, os estudantes ainda relataram que, durante o período em que estão na universidade para assistirem a suas aulas, locais como secretarias e colegiados ficam fechados, dificultando seu acesso às informações sobre possíveis eventos que acontecem, por exemplo.

Diante da maior participação dos estudantes do período diurno em atividades extracurriculares, os benefícios encontrados pelos universitários entrevistados por Cassundé et al. (2015), como a confiança de que o conhecimento e experiência adquiridos durante a atuação nesses projetos são potenciais colaboradores na elaboração da carreira profissional, tendem a ficar restritos aos mais ativos em tais atividades, no caso, aos alunos do matutino.

\section{CONCLUSÕES}

Ao considerar os dados analisados, são notadas diferenças significativas no perfil dos ingressantes em relação à idade, às pessoas com quem residem, ao modo como se preparam para as avaliações e à frequência na participação 


\section{MARCILIO, E. S. et al.}

em atividades extraclasse conforme comparados os turnos matutino e noturno. Esse conhecimento contribui para o desenvolvimento de estratégias de ensino diferenciadas e adaptadas a cada uma dessas realidades, principalmente no tocante ao período noturno, visto que, no geral, são os mais prejudicados pelo cansaço, pela dificuldade em participar de atividades extracurriculares e, principalmente, pelo pouco tempo para estudar fora da universidade, dado que muitos desses estudantes trabalham. Ademais, o fato de muitos dos acadêmicos do noturno serem mais maduros e entrarem na universidade com seus objetivos já delineados mostra a importância da elaboração de projetos e atividades que colaborem com esses objetivos, tornando, assim, as aulas mais atrativas para que consigam aproveitar melhor esse período na universidade.

\section{CONFLITOS DE INTERESSE}

Os autores declaram não haver conflito de interesse.

\section{REFERÊNCIAS}

AMORIN, A. F.; RODRIGUES, D.; RODRIGUES, M. Divergências entre o ensino diurno e noturno na disciplina de Química. In: Congresso Brasileiro de Química, 52º , 2012, Recife - PE. Anais... Recife: ASSOCIAÇÃO BRASILEIRA DE QUÍMICA.

CAMARGO, R. G.; SILVA, E. M. Aprendizagem de adultos e pensamento crítico nos cursos de Ciências Contábeis. In: PELEIAS, Ivam R. (Org.). Didática do Ensino da Contabilidade: Aplicável a outros Cursos Superiores. São Paulo: Saraiva, 2006. p. 225- 262.

CARDOSO, R. C. L.; SAMPAIO, H. Estudantes Universitários e o trabalho. Revista Brasileira de Ciências Sociais, São Paulo, Associação Nacional de PósGraduação em Ciências Sociais (Anpocs), v. 9, n. 26, out. 1994.

CARELli, M. J. G.; SANTOS, A. A. A. Condições temporais e pessoais de estudo em universitários. Psicol. Esc. Educ. (Impr.), Campinas, v. 2, n. 3, p. 265-278, 1998. Disponível em: http://www.scielo.br/scielo.php?script=sci arttext\&pid=S1413-85571998000300006\&lng=en\&nrm=iso. Acesso em: 13 maio 
2021.

CARVALHO, P. S. Hábitos de estudo e sua influência no rendimento escolar. 2012. Dissertação (Mestrado em Psicologia Clínica e da Saúde). Faculdade de Ciências Humanas e Sociais - Universidade Fernando Pessoa, Porto, 2012.

CASSUNDÉ, F. R. de S. A. et al. Participar ou não participar, eis a questão! Um estudo sobre o engajamento dos estudantes de administração em atividades extracurriculares. ID on line Revista de Psicologia, v. 9, n. 26, Supl. Esp., p. 4256, abr. 2015.

CLAUMANN, G. S. et al. Qualidade de vida em acadêmicos ingressantes em cursos de Educação Física. Journal of Physical Education, v. 28, n. 1, p. e-2824, 2017. Disponível em: https://periodicos.uem.br/ojs/index.php/RevEducFis/article/ view/32980. Acesso em: 17 jun. 2021.

COBO, B.; SOBOIA, A. L.; A “geração canguru” no Brasil. In: Encontro Nacional de Estudos Populacionais, 17., 2010, Caxambu, MG. Anais... Caxambu: ABEP, 2010. Sessão Temática 29.

CUNHA, M. I. Qualidade da graduação: o lugar do assessoramento pedagógico como propulsor da inovação e do desenvolvimento profissional docente. Educ. Rev., n. 57, p. 17-31, 2015. DOI: https://doi.org/10.1590/0104-4060.42106.

FRAGA, C. K.; OLIVEIRA, A. F. R.; SEBASTIANY, M. M. Perfil socioeconômico das/os estudantes de serviço social da Universidade Federal de Santa Maria. Artigo Livre. Revista Sociais \& Humanas, v. 31, n. 2, p. 214, 2018.

HENRIQUES, C. R.; FÉRES-CARNEIRO, T.; MAGALHÃES, A. S. Work and family: the extending of family life in question. Paidéia (Ribeirão Preto), [S. l.], v. 16, n. 35, p. 327-336, 2006. DOI: 10.1590/S0103-863X2006000300004. Disponível em: https://www.revistas.usp.br/paideia/article/view/6403. Acesso em: 17 jun. 2021.

KRUG, R. R.; KRUG, H. N. Os Motivos da Escolha da Profissão: Licenciatura ou Bacharelado em Educação Física. Revista Gestão Universitária, 2017. Disponível em: http://www.gestaouniversitaria.com.br/artigos/os-motivos-da- 


\section{MARCILIO, E. S. et al.}

escolha-da-profissao-licenciatura-ou-bacharelado-em-educacao-fisica. Acesso em: 17 jun. 2021.

MARANHÃO, J. D.; VERAS, R. M. O ensino noturno na Universidade Federal da Bahia: percepções dos estudantes. Ensaio: Aval. Pol. Públ. Educ., v. 25, n. 96, p. 553-584, Sep. 2017.

MOREIRA, L. J.; GOMES, T. S. Determinantes do desempenho acadêmico do estudante trabalhador e do trabalhador estudante. Orientador: Sandro César Bortoluzzi: 2018. 77 f. Trabalho de Conclusão de Curso (Graduação) Universidade Tecnológica Federal do Paraná, Pato Branco, 2018.

MOURA, A. C. R.; MIRANDA, G. J.; PEREIRA, J. M. Desempenho acadêmico em ciências contábeis: turno noturno versus diurno. Ref. Cont. UEM - Paraná, v. 34, n. 1, p. 57-70, jan./abr. 2015.

PATTO, T. L. S.; FERRO, D. P.; AIRES, G. S. B. Comparação do perfil dos alunos ingressantes do curso de medicina veterinária do Centro Regional Universitário de Espírito Santo do Pinhal/SP. Congresso Nacional de Educação, 2017. Disponível em: http://www.educacaopocos.com.br/Anais/trabalhos. Acesso em: 17 jun. 2021.

PIAZZA, B. L.; REPPOLD FILHO, A. R. O ensino de anatomia humana nos cursos de Educação Física da região metropolitana de Porto Alegre. Ciência em movimento, v. 13, n. 26, p. 99-109, 2011.

PINTO, A. et al. A. Barreiras percebidas para a prática de atividade física entre universitários de Educação Física. Rev Bras Ativ Fís Saúde, v. 22, n 1, p. 66-75, 2017.

SALBEGO, C. et al. Percepções acadêmicas sobre o ensino e a aprendizagem em anatomia humana. Revista Brasileira de Educação Médica, v. 39, n. 1, p. 23-31, 2015.

SANTOS, A. M. P. V. dos. et al. O processo de ensino e aprendizagem de anatomia humana: uma avaliação de estratégias. Revista Ensino, Saúde e Ambiente, v.13, n. 3, p. 362-372, dez. 2020. 
SILVA, F. K. Perfil dos alunos ingressantes em 2018 no curso de Ciências Contábeis com risco de evasão de acordo com o modelo de Tinto (1997). 2019. Orientadora: Daniele da Rocha Carvalho. 72f. Trabalho de Conclusão de Curso (Graduação em Ciências Contábeis) - Departamento de Ciências Contábeis, Centro de Ciências Sociais Aplicadas, Universidade Federal do Rio Grande do Norte, Natal, 2019.

SOUZA, I. M. de. et al. O curso de administração da Universidade Federal de Santa Catarina - O perfil dos prováveis formandos. Revista GUAL, Florianópolis, v. 9, n.1, p.60-81, jan. 2016.

UEL, Universidade Estadual de Londrina (Brasil, Londrina, Paraná). Catálogo dos cursos de graduação 2020: Educação Física: Habilitação - Bacharelado. Londrina, 2021a. Disponível em: http://www.uel.br/prograd/?content=catalogocursos/catalogo_2020/cursos/educacao_fisica_bacharelado.html. Acesso em: 26 mar. 2021.

UEL, Universidade Estadual de Londrina (Brasil, Londrina, Paraná). Conheça a UEL: Missão, Finalidades e Princípios. Londrina, 2021b. Disponível em: https:// portal.uel.br/conheca-a-uel/pages/missao.php. Acesso em: 26 mar. 2021.

UNESCO. ABRAMOVAY, M.; CASTRO, M. G. (Coord.). Juventude, juventudes: o que une e o que separa. Brasília: Edições UNESCO, 2006. Disponível em: http://www.dominiopublico.gov.br/pesquisa/DetalheObraForm.do? select_ action=\&co_obra=64654. Acesso em: 17 jun. 2021.

Recebido em: 20/08/2021

Aceito em:19/11/2021 